\title{
Biological correlates of migraine and cluster headaches: an overview of their potential use in diagnosis and treatment
}

REVIEW

This article was published in the following Dove Press journal:

Pragmatic and Observational Research

3 December 2010

Number of times this article has been viewed

\section{Aron D Mosnaim' \\ Javier Puente ${ }^{1,2}$ \\ Marion E Wolf ${ }^{3}$}

'Department of Cellular and Molecular Pharmacology, Rosalind Franklin University, Chicago Medical School, Chicago, IL, USA; ${ }^{2}$ Faculty of Chemical and Pharmaceutical Sciences, University of Chile, Santiago, Chile; ${ }^{3}$ International Neuropsychiatry Consultants, Highland Park, IL, USA

Correspondence: Aron D Mosnaim Neuroimmunopharmacology Laboratory, Rosalind Franklin University of Medicine and Science, The Chicago Medical School, 3333 Green Bay Road, N. Chicago, Illinois 60064, USA

Tel +l 8475788675

Fax + I 8475783268

Email aron.mosnaim@rosalindfranklin.edu
Abstract: Current diagnostic criteria for headaches are based on the International Classification for Headache Disorders, second edition, which is largely built on data obtained from clinical examinations and patients' medical histories. Despite decades of vigorous basic and clinical research, we still lack reliable clinical laboratory diagnostic markers for headaches, which clearly obstructs the physician's ability to optimize and follow the patient's response to treatment protocols as well as holds back the discovery and implementation of new therapeutic modalities. In this paper, we review and discuss current efforts to identify and characterize biochemical and immunological changes in biological fluids and tissue that may be specifically associated with the etiology and/or pathophysiology of migraine and cluster headaches; we also discuss some of the recent genetic findings and ion channel modulation studies that may help to distinguish among various headache populations.

Keywords: biochemical, immunological, genetic alterations, pain, enkephalin degradation kinetics, enkephalin aminopeptidase

\section{Migraine and cluster headaches: clinical laboratory search for biological markers}

Current diagnostic criteria for migraine and cluster headaches $(\mathrm{CHs})$ are based on the International Classification for Headache Disorders, second edition (ICHD-2). ${ }^{1}$ Diagnosis of these conditions is largely based on data obtained from clinical examination and the patient's medical history, particularly features of the associated pain, eg, location, intensity, and time pattern. A lack of valid clinical laboratory diagnostic markers clearly obstructs the physician's ability to optimize and follow the patient's response to treatment protocols, as well as holds back the discovery and implementation of new therapeutic modalities. To a significant extent, clinical laboratory research on headaches has been focused on identifying and characterizing biochemical and immunological changes in biological fluids and tissue that may be specifically associated with the etiology and/or pathophysiology of migraine and CHs. The most commonly studied samples and specimens are blood, urine, saliva, skin, cerebrospinal fluid (CSF), and smooth muscle. ${ }^{3-5}$

Current migraine and $\mathrm{CH}$ research is largely directed at identifying the vulnerability to, and triggers of, these conditions; understanding the transmission of the nociceptive information; ${ }^{6,7}$ and elucidating the role of vascular, neural, and peripheral and/or central sensitization mechanisms for their generation. ${ }^{8}$ 


\section{Vasoactive amines and some of their metabolites}

Early research was mostly directed at elucidating the role of vasoactive amines as triggers for these disorders. Initial work on histamine was soon expanded to include other endogenous amines, such as the catecholamines, serotonin, tyramine, and phenylethylamine, as well as some of their metabolites, including 3-methoxy, 4-p-hydroxyphenylacetic acid, 5-hydroxyindolacetic acid, p-hydroxyphenylacetic acid, and phenylacetic acid..$^{9-12}$ Study of the enzymes responsible for amine degradation was mainly centered on the examination of platelet monoamine oxidase (MAO) activity during the various phases of migraine and $\mathrm{CHs}$. The human platelet enzyme is known to play a nonspecific "scavenger" role in the metabolism of circulating type B, but not type A, substrates. For example, it degrades tyramine, phenylethylamine, and dopamine but does not metabolize serotonin to any significant extent. ${ }^{13-16}$

This line of research has been relatively unsuccessful in providing the hoped for biological markers that could be used in the clinical diagnoses of migraine and $\mathrm{CHs}$; however, it has offered the theoretical framework to discuss the mechanism of action of some of the drugs most widely used for the acute and prophylactic treatment of migraine and CHs. ${ }^{17}$ It is widely recognized that a blend of extraordinarily perceptive clinical observations started by Graham and Wolff ${ }^{2}$ and basic research ranging from classical tissue-response studies to the molecular characterization and cloning of various serotonin receptors has led to a better understanding of the mechanism of action of a number of drugs used in the treatment of migraine and CHs. ${ }^{5}$ This new and evolving knowledge also holds the promise for the rational design of new, more specific pharmacotherapeutic treatments for these illnesses. However, and as a cautionary observation, we do not have unequivocal support for the notion that there is an association between alterations in plasma vasoactive monoamine levels and the occurrence of migraine headaches. ${ }^{5,14,16}$

\section{Other vasoactive substances}

The role of vasoactive substances other than monoamines, such as different peptides and nitric oxide, ${ }^{18}$ in the etiology of headaches and accompanying pain has been the subject of numerous studies yielding rather contradictory results. Ongoing research on the development of specific receptor ligands and/or blockers for these substances may lead to novel therapeutic treatments for migraine..$^{19,20}$

\section{Prostanoids and other inflammatory mediators}

Despite extensive research and abundant literature, the precise role of inflammation in the pathophysiology of migraine and $\mathrm{CHs}$, particularly the associated pain, remains elusive. A metaanalysis of current literature indicates that the inflammatory processes possibly involved in these headaches are not likely to be of immune origin. ${ }^{21}$ Specifically, the role of changes in the circulating levels of endogenous proinflammatory agents (eg, kinins, prostaglandings, and cytokines) is being studied. Preliminary results indicate that novel antinociceptive agents that are able to modulate $G$ protein-coupled receptors' response to these chemicals are being developed. ${ }^{22}$

\section{Some enzymatic systems and substrates involved in the arachidonic acid pathway}

Efforts to elucidate the involvement of arachidonic acid metabolites, particularly those active in lipoxygenase pathways, in the pathogenesis of migraines and $\mathrm{CHs}$ have yielded some interesting, albeit preliminary, results. ${ }^{23}$ Plasma levels of leukotriene B4, a potent proinflammatory mediator produced in part by polymorphonuclear leukocytes, have been reported to be significantly increased during an acute $\mathrm{CH}$ episode. No changes in this substance were found in migraineurs, either during an acute episode or when the patient was "pain-free". ${ }^{24}$ Further research in this area ought to be encouraged, as these substances (eg, leukotrienes) play an important role in inflammatory and allergic processes. It is suggested that these substances may influence the changes in platelet aggregability associated with the different phases of classical migraine. ${ }^{25}$

\section{Psychoendocrinological studies}

Recent dramatic and continuing advances in psychoneuroendocrinology have encouraged exploration of the rather inclusive hypothesis that alterations in hormonal levels might be associated with the pathogenesis of migraine and $\mathrm{CHs}^{26}$ However, neither the measurement of the circulating concentration of a variety of hormones and hormone-stimulating and -releasing factors (eg, testosterone, prolactin, cortisol, growth hormone, thyroid hormone, thyroid stimulating, and releasing hormone) nor the results from a number of openfield, adrenal-hypothalamic-pituitary challenge tests have produced unequivocal data to support such a hypothesis. Nevertheless, research in this area continues to attract the interest of investigators trying to explain the findings of 
increased male vulnerability to $\mathrm{CHs}$ and the increasing body of evidence linking biochemical changes associated with pregnancy, stress, and menstruation on the occurrence and severity of migraine headaches. ${ }^{3,26,27}$ The variables of this research, in both the clinical and laboratory sense, make clear the need for a large-scale multicenter study to provide definitive data on the possible relationship between endocrinological changes and the pathophysiology of migraine and CHs. Alterations in sex hormones have been shown to affect peripheral and central pain-processing mechanisms. Thus, such changes may modulate migraine-associated pain. ${ }^{28}$

\section{Immunological studies and viral studies}

Attempts to implicate viral infections in the etiology of certain headaches have met with little success. Based mostly on a series of isolated, largely nonreplicated, observations, it has been suggested that "the persistence and reactivation of classic viruses may be responsible for some chronic headache syndromes and their exacerbations". ${ }^{29}$ Vanast et al reason that virus-lymphocyte contact leading to cytokine release and antibody production may ultimately produce selected inflammation, and it is this tissue damage that is responsible for the triggering of headaches. They hypothesized that "chronic benign daily headaches, in particular, is an immune disorder with a viral trigger".

Several lines of research suggest an association between the occurrence of migraine and $\mathrm{CHs}$ and changes in a number of immune functions. ${ }^{24,30-34}$ It has been reported that migraine or related phenomena is an initial and prominent indication for the presence of antiphospholipid antibodies, a term encompassing a variety of spontaneously acquired immunoglobulins that may be seen in a number of rheumatological conditions. Based on these immunological findings, it has been suggested that the classification of these patients is a subcategory of migraine. Furthermore, the possibility has been raised that early diagnoses of this association could be a useful clinical tool in identifying headache patients at risk for the development of other serious conditions, in particular collagen vascular diseases. ${ }^{35}$

Examination of immunological functions in headache patients has been carried out using different research approaches. Thus, after finding that individuals suffering from migraines, chronic tension headaches, or both of these conditions have a significant decrease in the absolute number of T8 and a higher T4:T8 lymphocyte ratio, Gilman-Sachs et al suggested a relationship between "certain abnormalities in the immune system" and the cause of chronic headaches. ${ }^{36}$ These authors also reported the failure to find significant changes in the number of cells bearing a number of other markers, such as T3, T4, T11, B1, NKH-1, 12, or M02. Giacovazzo et $\mathrm{al}^{37}$ studied different subpopulations of T lymphocytes and monocytes (eg, Leu1, Leu2a, Leu3a, Leu7, and LeuM3), as well as antigens of the human major histocompatibility complex (eg, HLA, B, C, and DR), in episodic $\mathrm{CH}$ patients. During the attack phase, DR5- and DR5+ patients showed an increase in the number of LeuM3+ or Leu7+ cells, respectively. Outside of the acute episode, $\mathrm{DR}+$ subjects had an increase in the number of LeuM3+ cells. Based on these findings, and similar previously reported results, the authors speculated about the possible role of some Class II antigen (HLA-DR) combinations as genetic markers for $\mathrm{CH}$. However, and in a related familial study, these researchers failed to identify a particular HLA antigen or haplotype that could serve as a genetic marker for migraine. ${ }^{37}$

Based mostly on open-field studies, circumstantial evidence, and anecdotal reports, allergic processes have been suggested as one of the many migraine and $\mathrm{CH}$-precipitating factors. ${ }^{38}$ In this proposed model, increases in the availability of histamine (a monoamine known for both its role as a chemical mediator of hypersensitivity reactions and its potent vasodilator effects) would provide the chemical link between allergy and headaches. However, neither the examination of the plasma concentration of a number of serum complement components (eg, $\mathrm{Cl}_{\mathrm{q}}, \mathrm{C} 3, \mathrm{C} 4$, and factor $\mathrm{B}$ ) nor the detection studies of a range of immune complexes (very small IgG to larger IgM), has provided significant differences between cluster and migraine headache patients (including some individuals suggested to suffer from food-induced allergic migraine) and controls. ${ }^{39}$

Findings that the activity of natural killer cells (NKCs) in $\mathrm{CH}$ patients, either during or outside of an acute headache attack, were significantly decreased in respect of sexmatched, age-comparable controls (non- $\mathrm{CH}$ patients) led to the suggestion that this cellular immune function could serve as a "trait biological marker" for this condition. ${ }^{37}$ In related experiments, Martelletti et al found that the relative increases in NKC activity in response to incubation with $\mathrm{B}$-interferon were significantly higher in the $\mathrm{CH}$ patients than in the controls. ${ }^{40}$ Following this experimental line, the same group reported that the generation of lymphokineactivated killer cells produced by the incubation of peripheral blood lymphocytes with recombinant interleukin (IL)-2 
was markedly increased in cluster patients when compared with controls. ${ }^{40}$ We failed to find statistically significant differences in baseline NKC activity between groups of migraineurs (either during or outside of a migraine attack) and sex-matched, age-comparable controls. However, preincubation of samples obtained from patients during an acute migraine episode with methionine-enkephalin (MET) or B-endorphin resulted in a significant downmodulation of NKC activity. ${ }^{30,31}$ Although much work is needed before a rational assessment can be made of the possible relationship between NKC activity and the occurrence of cluster and migraine headaches, it seems that variations in this immunological parameter may reflect some of the biochemical changes associated with these headaches. It has been evident for years that physically and psychologically stressful events can trigger the occurrence of headaches, but only recently have we discovered that these events can also modify the response of some cellular and humoral immune functions. However, little is known about the nature and mechanism of action of the mediators in the bidirectional interactions between the central nervous system and the immune system and which role, if any, they may have in the pathophysiology of headaches. This is a relatively new area of insight into the relationship between changes in the immune system and the occurrence of headaches..$^{24,30-34}$

\section{Genetic studies and ion channel involved in pain modulation}

It has been long recognized, mostly through familial and epidemiological studies, that hereditary factors play an important role in patients' vulnerability to migraine. ${ }^{41}$ Thus, most of the headache genetic research has been conducted in individuals suffering from migraine or afflicted with familial hemiplegic migraine (FHM). ${ }^{42}$ There have been relatively few genetic studies on $\mathrm{CH}$ patients. ${ }^{43}$ Using different approaches, scientists have examined the prevalence of these conditions in diverse populations, followed familial and twin protocols, and looked into their molecular mechanisms and mode of inheritance. ${ }^{44}$ Linkage analysis has identified various "migraine genes or loci" with significant mutations, including the identification of the CACNA1 A gene (located in chromosomes 19p13 of FHM patients), which has been suggested as the first "migraine gene". ${ }^{43}$ Related work has led to the suggestion that "ion channels could play a role in migraine" and, for the purpose of further research, to consider FHM as a channelopathy. ${ }^{45}$

Association studies, particularly with various hereditary diseases frequently seen in migraineurs, have provided evidence for a positive or suggestive relation with a significant number of genes. Genetic research in migraines and other headaches has produced a great deal of promising information, but present results can be considered only preliminary in nature, ${ }^{44}$ reflecting the significant methodological and logistic difficulties encountered in such research.

\section{Endogenous peptides with opioid-like activity}

Although the aim of most current efforts on basic migraine and $\mathrm{CH}$ research continues to be the elucidation of the mechanism(s) responsible for triggering, developing, and sustaining these conditions, ${ }^{5}$ an increasing number of studies have been directed toward a better understanding of the processes involved in the abnormal modulation of the pain response observed in these patients. ${ }^{3,27,46-48}$ Knowledge in this area was greatly enhanced by the discovery in the early 1970s that widely used opioid-like pain medications such as morphine and codeine exert their analgesic effects through interactions with specific central nervous system-located postsynaptic receptors and by the subsequent isolation and identification in brain tissue of chemicals whose physiological actions at these receptors mimic those of morphine. ${ }^{49}$ Unexpectedly, the chemical structure of the endogenous antinociceptive substances was drastically different from that of morphine (itself an alkaloid). Previous searches for "the endogenous morphine" have been focused on morphine-like chemicals, thus leading to a number of false starts in the search for the elusive endogenous morphine painkillers. The initial discovery of the relatively simple pentapeptides MET (tyr-gly-gly-phe-met) and leucine-enkephalin (LEU) (tyr-glygly-phe-leu) was rapidly followed by the isolation of at least 20 different endogenous peptides with analgesic effects. ${ }^{47}$

There is a general, and erroneous, tendency to accept that the endorphins, dynorphins, and enkephalins present similar and rather undistinguishable biological profiles. However, these classes of endogenous peptides, derived from a distinct gene family, arise from the processing of a different parent polyprotein precursor (eg, proenkephalin, proopiomelanocortin, and prodynorphin, respectively) and show significant differences in their biochemical properties, physiological functions, and pharmacological effects. ${ }^{47}$ The endorphins are products of the pro-ACTH gene, which is expressed in the brain and pituitary. The enkephalins are products of the pro-enkephalin gene, which is expressed in the pituitary and various other brain areas such as the spinal cord, and in large amounts in the adrenal medulla. Furthermore, the pro-dynorphin gene is expressed in a 
number of tissues, including the brain. At the molecular level, these peptides may act upon at least five different classes of opiate receptors (mu, kappa, sigma, delta, and epsilon), and in addition to pain modulation they may have a wide variety of seemingly unconnected biological roles, including controlling thirst, hunger, and libido. ${ }^{49}$ The role of MET in human pain modulation has been given support from longitudinal studies showing that acute migraine episodes are accompanied by significant increases in plasma MET levels, which in most cases return to "normal" values after several days to 3 weeks of the acute episode. ${ }^{50}$ Furthermore, results from research including $\mathrm{CH}$ patients showed that the occurrence of an acute $\mathrm{CH}$, within a cluster series, is accompanied by rapid and significant changes in plasma MET levels. Plasma peptide concentration is elevated shortly prior to an attack, returning to values similar to "normal" during the attack and falling below the range of "normal" immediately after the acute $\mathrm{CH}$ episode. In a typical case, blood was drawn (2:00 PM; precluster phase) from a subject who believed that an acute attack was imminent (it occurred about 90 minutes later), followed by a second at 4:00 PM (during a CH attack), and a third drawing at 6:00 PM (postcluster phase). ${ }^{51}$

These studies, showing dramatic changes in circulating MET levels in response to migraine and $\mathrm{CH}$ attacks, lend support to the hypothesis that "the alterations in the neurovegetative system and anhedonia, as well as increased awareness and/or lower threshold to pain associated with the occurrence of a migraine or $\mathrm{CH}$ attack, are due to a failure of the opiate-peptide system to properly modulate sensitivity to pleasure and pain". ${ }^{46,47,50,51}$ If we accept the presence in these patients of a dynamic equilibrium between the building up of processes ultimately leading to pain expression and of the body response to these pathophysiological changes, it could be hypothesized that the relative changes in circulating MET levels could be viewed as modulating the outcome of this challenge. It could be suggested that the increase in plasma MET observed during an acute migraine episode was not sufficient to abort the associated pain, and one can also speculate at least in some instances that the changes in MET bioavailability could result in painless migraine or $\mathrm{CH}$ episodes. In these patients, the response of the enkephalins and/ or other endogenous opioids overcomes the manifestation of pain. ${ }^{50,51}$ Thus, one could suggest that the dramatic increase in circulating enkephalins observed during the precluster phase of a $\mathrm{CH}$ episode was not sufficient to abort the pain experienced during the headache attack. The levels of enkephalin appear to rise before the appearance of the full cluster attack to protect the individual from the pain. ${ }^{51}$
Based largely on animal studies showing analgesic properties for MET and LEU, it has been suggested that blocking their degradation would lead to novel antinociceptive agents. However, in the search for such agents, most studies failed to recognize differences amongst the various animal species studied. In some species, these peptides were degraded by a combination of dipeptidyl carboxy peptidase, dipeptidyl amino peptidase, and aminopeptidase(s), but, in humans, the enkephalins are essentially completely metabolized by aminopeptidase(s). ${ }^{52-54}$ Thus, MET incubation with human plasma, brain tissue, or CSF samples results in the rapid and essentially complete hydrolysis of the tyrosineglycine bond. No significant amounts of other MET metabolites were detected. ${ }^{52-54}$ Therefore, studies should focus on developing effective, specific enkephalin (MET and LEU) aminopeptidases inhibitors. Following this reasoning, we have studied the effect of a significant number of agents, including over 200 clinically used drugs with widely different chemical structures and pharmacological profiles, on the rate of in vitro peptide degradation. ${ }^{55-58}$ We have identified a small number of substances with the phenothiazine molecule in their chemical structure, at least one specific serotonin reuptake inhibitor (fluvoxamine), and various small endogenous peptides able to significantly reduce the rate of plasma and brain aminopetidase MET and LEU degradation (see Figure 1). ${ }^{55-58}$

These findings could prove useful in helping clinicians to better identify the different phases of cluster and migraine headaches. Furthermore, the relative increases in plasma peptide levels during an acute headache episode could indicate the severity of headache pain in so helping physicians to select the appropriate medication and dose. Use of aminopeptidase inhibitors to modulate MET and LEU availability could be useful in the treatment of headacheassociated pain. Whether development of such drugs could find useful pharmacological applications remains to be explored.

\section{Neurotrophins and cytokines}

Decreased brain-derived neurotrophic factor (BDNF) and nerve growth factor (NGF) levels in platelets of primary, but not $\mathrm{CH}$ patients, has raised the suggestion that these neurotrophins could serve to differentiate migraineurs from individuals suffering from $\mathrm{CH}^{59}$ Findings of increased CSF's glutamate, BDNF, and NGF concentration in chronic migraineurs would indicate the involvement of these substances in the pain associated with this condition. ${ }^{60} \mathrm{~A}$ broader study, however, failed to detect significant differences in CSF's BDNF and NGF 


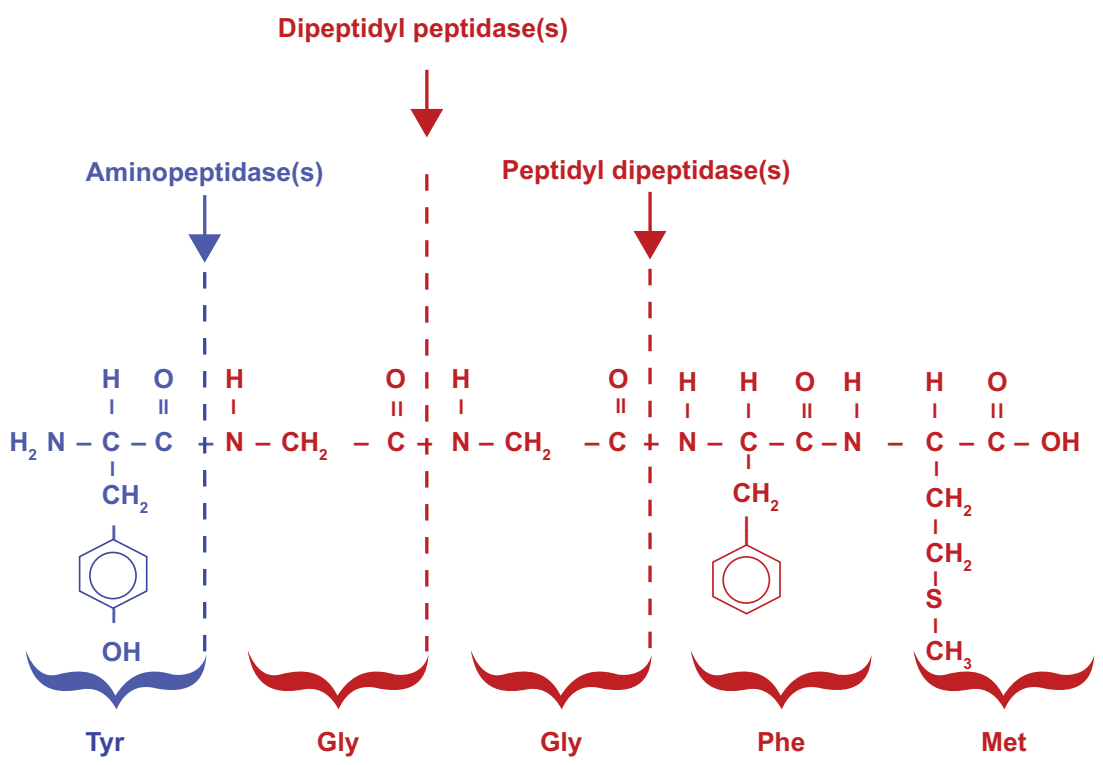

Chemical structure of methionine ${ }^{5}$ enkephalin. Enzymes responsible for its metabolism.

Figure I Puromycin-sensitive aminopeptidase(s) tyrocine glycine hydrolysis: predominant step in in vitro human brain methionine-enkephalin metabolism. ${ }^{56}$ Copryight @ Lippincott Williams \& Wilkins. Reproduced with permission from Mosnaim AD, Puente J, Hoang C, Ranade V, Wolf, ME. Inhibition of human plasma leucineenkephalin aminopeptidase hydrolysis by various endogenous peptides and a select number of clinically used drugs. American J Therap. 2004;। I:459-465.

levels, as well as ciliary and cell-line neurotrophic factor levels, between controls and patients diagnosed with either neuropathic or nociceptive pain, stressing the need for further research in this area. ${ }^{61}$ Exploration of the possible role of cytokines, a general name covering an increasing number of regulatory proteins, eg, ILs and lymphokines, in the pathophysiology of migraine headaches has produced some interesting and sometimes conflicting, albeit preliminary, results. Thus, levels of IL-4 and IL-5, but not IL-10 or interferon-gamma, were increased during the interictal period in the plasma of migraine without aura patients. ${ }^{62}$ Moreover, when compared with controls or pain-free migraineurs, the levels of IL-10 appear to be increased in the plasma of patients during an acute migraine episode. ${ }^{63}$ Research on cytokines and other regulatory proteins released by cells of the immune system will hopefully provide a useful insight into the mechanism responsible for the pathogenesis of migraine and $\mathrm{CH}^{64}$

\section{Acknowledgments}

Portions of this paper were presented at the course Neurobiologic Mechanisms as an Approach to the Pharmacology of Headache: Amer Soc Clin Pharmacol Therapeutics Annual Meeting (1991), and published (Solomon GD, editor) in Headache Quart, Curr Treat Res. 1992;3(3):309-311. They were also published in Mosnaim AD: Biochemical and immunological studies in migraine and cluster headaches.
In: New and Old Therapies of Vascular Headaches: Immune Approaches and Serotonin Receptors in Therapy (Mosnaim AD, editor). Headache Quart, Curr Treat Res. 1994;5(1):34-38. They are included in this manuscript with permission.

This work was supported, in part, by The National Headache Foundation.

\section{Disclosure}

The authors report no conflicts of interest in this work.

\section{References}

1. Headache Classification Committee of the International Headache Society. The International Classification of Headache Disorders: 2nd edition. Cephalalgia. 2004;24 Suppl 1:9-160.

2. Graham JR, Wolff HG. Mechanisms of migraine headache and action of ergotamine tartrate. Arch Neural Psychiat. 1938;39:737-763.

3. Mathew NT. Cluster Headaches. New York: SP Medical and Scientific Books; 1984.

4. Sarchielli P, Bach FW. Blood and spinal fluids in migraine. In: Olesen J, Goadsby PJ, Ramadan NM, Tfelt-Hansen P, Welch MA, editors. The Headaches. 3rd ed. Philadelphia: Lippincott, Williams \& Wilkins; 2006: chapter 34.

5. Olesen J, Goadsby PJ, Ramadan NM, Tfelt-Hansen P, Welch, MA, editors. The Headaches. 3rd ed. Philadelphia: Lippincott, Williams \& Wilkins; 2006: chapters 9-23, 27.

6. Sandkuhler J. The organization and function of endogenous antinociceptive systems. Prog Neurobiol. 1996;50:49-81.

7. Messlinger K, Dostrovsky JO, Strassman AM. Anatomy and physiology of headache pain. In: Olesen J, Goadsby PJ, Ramadan NM, Tfelt-Hansen P, Welch MA, editors. The Headaches. 3rd ed. Philadelphia: Lippincott, Williams \& Wilkins; 2006: chapter 10. 
8. Johnson KW, Bolay H. Neurogenic inflammatory mechanisms. In: Olesen J, Goadsby PJ, Ramadan NM, Tfelt-Hansen P, Welch MA, editors. The Headaches. 3rd ed. Philadelphia: Lippincott, Williams \& Wilkins; 2006: chapter 33.

9. Mosnaim AD, Wolf ME, editors. Non-catecholic Phenylethylamines. Part 1: Phenylethylamine: Biological Mechanisms and Clinical Aspects. New York: Marcel Dekker, Inc; 1978.

10. Mosnaim AD, Wolf ME, editors. Non-catecholic Phenylethylamines. Part 2: Phenylethanolamine, Tyramines and Octopamine. New York: Marcel Dekker, Inc; 1980.

11. Mosnaim AD, Wine R, Karoum F, Diamond S, Wolf ME. Methionineenkephalin, phenylelthylamine, phenylacetic acid, platelet monoamine oxidase and prolactin in plasma of migraine patients. Clin Pharmacol Ther. 1982;31:251-252.

12. Mosnaim AD, Wolf ME, Diamond S. Non-catecholic phenylethylamines and MAO activity in diabetes and migraine. In: Boulton A, Baker G, Dewhurst W, Sandler M, editors. Neurobiology of Trace Amines. New Jersey: Humana Press; 1984:549-556.

13. Yang H-YT, Neff NH. Phenylethylamine: a specific substrate for type B monoamine oxidase. J Pharmacol Exp Ther. 1973;187. 365-371.

14. Mosnaim AD, Karoum F, Zeller EA, Callaghan OH, Singh Z, Wolf ME. Platelet monoamine oxidase activity and plasma levels of non-catecholic phenylethylamines in insulin-dependent diabetes. Clin Chim Acta. 1982; 126:237-242.

15. Mosnaim AD, Huprikar S, Wolf ME, Callaghan OH, Freitag FG, Diamond S. Platelet monoamine oxidase activity in cluster headache patients. Headache Quart. 1992;3:172-176.

16. D'Andrea G, Terrazzino S, Leon A, et al. Elevated levels of circulating trace amines in primary headaches. Neurology. 2004;62: 1701-1705.

17. Waeber C. Serotonin and other biogenic amines. In: Olesen J, Goadsby PJ, Ramadan NM, Tfelt-Hansen P, Welch MA, editors. The Headaches. 3rd ed. Philadelphia: Lippincott, Williams \& Wilkins; 2006: chapter 14.

18. Brain S, Edvinsson L. Calcitonin gene-related peptide and other peptides. In: Olesen J, Goadsby PJ, Ramadan NM, Tfelt-Hansen P, Welch MA, editors. The Headaches. 3rd ed. Philadelphia: Lippincott, Williams \& Wilkins; 2006: chapter 16.

19. Olesen J, Iversen HK, Thomsen LL. Nitric oxide supersensitivity; a possible molecular mechanism of migraine pain. Neuroreport. 1993; 4:1027-1030.

20. Bartsch T, Akermam S, Goadsby PJ. The ORL-1 (NOP1) receptor ligand nociceptin/orphanin FQ (N/OFQ) inhibits neurogenic dural vasodilation in the rat. Neuropharmacology. 2001;43:991-998.

21. Kemper RH, Meijler WJ, Korf J, Ter Horst GJ. Migraine and function of the immune system; a meta analysis of clinical literature published between 1966 and 1999. Cephalalgia. 2001;21:549-557.

22. Reuter U, Chiarugi A, Bolay H. Nuclear factor-kappaB as a molecular target for migraine therapy. An Neurol. 2002;51:507-516.

23. Gazzaniga PP, Ferroni P, Lenti L, et al. Identification of blood leukotrienes in classical migraine. Headache. 1987;27:211-215.

24. Selmaj K, de Beleroche J, Das I, Rose FC. Leukotriene B4 generation by polymorphonuclear leukocytes: Possible involvement in the pathogenesis of headache. Headache. 1986;26:460-464.

25. LaMancusa R, Pulcinelli FM, Ferroni P, et al. Blood leukotrienes in headache: correlation with platelet activity. Headache. 1991;31: 409-414.

26. Berman NEJ, Behbehani MM. Sex hormones. In: Olesen J, Goadsby PJ, Ramadan NM, Tfelt-Hansen P, Welch MA, editors. The Headaches. 3rd ed. Philadelphia: Lippincott, Williams \& Wilkins; 2006: chapter 17

27. Fillingim R, Ness TJ. Sex-related hormones influences on pain and analgesic responses. Neurosciences Biobehav Rev. 2000;24:485-501.

28. Calizo LH, Flanagan-Cato LM. Estrogen-induced dendritic spine elimination on female rat ventromedial hypothalamic neurons that project to the periaqueductal gray. J Comp Neurol. 2002;447:234-248.
29. Vanast WJ, Diaz-Mitoma F, Tyrrell DLJ. Hypothesis: chronic benign daily headache is an immune disorder with a viral trigger. Headache. 1987;27:138-142.

30. Mosnaim AD, Wolf ME, Maturana P, Puente J, Freitag F, Diamond S. In vitro studies natural killer cell activity in migraineurs. Changes in response to methionine enkephalin challenge during an acute migraine episode. Headache Quarterly. 1993;4:36-41.

31. Mosnaim AD, Wolf ME, Maturana P, Puente J, Freitag F, Diamond S. In vitro studies of natural killer cell activity in migraineurs. Changes in response to a B-endorphin challenge during an acute migraine episode. Headache Quarterly. 1994;5:142-148.

32. Mosnaim AD, Kulaga H, Adams AJ, et al. Flow cytometric analysis of lymphocytes subsets in migraine patients during and outside of an acute headache attack. Cephalalgia. 1998;18:197-201.

33. Waldenlind E, Bussone G. Biochemistry, Circannual and circadian rhythms, endocrinology, and immunology of cluster headaches. In: Olesen J, Goadsby PJ, Ramadan NM, Tfelt-Hansen P, Welch MA, editors. The Headaches. 3rd ed. Philadelphia: Lippincott, Williams \& Wilkins; 2006: chapter 88.

34. Puente J, Jaque M, Carolina C, et al. Triptan drugs, natural killer cell cytotoxicity, and neutrophils prp-matrix metalloproteinase-9 secretion. Headache. 2008;48,1482-1489.

35. Shuaib A, Barklay L, Lee MA, Suchowersky O. Migraine and antiphospholipid antibodies. Headache. 1989;29:42-45.

36. Gilman-Sachs A, Robbins L, Baum L. Flow cytometric analysis of lymphocyte subsets in peripheral blood in chronic headache patients. Headache. 1989;29:290-294.

37. Giacovazzo M, Martelletli P, Valeri M, Piazza A, Casciani CU. A new immunological aspect of cluster headache: the increase of monocyte and NK cell populations. Headache. 1986;26:134-136.

38. Shapiro RS. Allergic headache. In: Vinken PJ, Bruyn GW, editors. Handbook of Clinical Neurology, Volume V. Amsterdam: North Holland Publishing; 1976.

39. Visintini D, Trabattoni G, Manzoni GC, Lechi A, Bortone L, Behan PO. Immunological studies in cluster headache and migraine. Headache. 1986;26:398-402.

40. Martelletti P, Valeri M, Piazza A, Monaco PI, Casciani CU. Variations in the Leu7+ and LeuM3+ leukocyte subpopulations observed in cluster are dependent on HLA.DR antigens. Headache. 1987;27:35-38.

41. Russell MB. Generic epidemiology of migraine and cluster headache. Cephalalgia. 1997;17:683-701.

42. Ophoff RA, Terwindt GM, Vergouwe MN, et al. Familial hemiplegic migraine and episodic ataxia type- 2 are caused by mutations in the Ca+2 channel gene CACNL1 A4. Cell. 1996;1:543-552.

43. Kudrow J, Kudrow DH. Inheritance of cluster headache and its possible link to migraine headache. Headache. 1994;34:400-407.

44. Ferrari MD, Haan J, Palotie A. Genetics of migraine. In: Olesen J, Goadsby PJ, Ramadan NM, Tfelt-Hansen P, Welch MA, editors. The Headaches. 3rd ed. Philadelphia: Lippincott, Williams \& Wilkins; 2006: chapter 27.

45. Akerman S, Williamson DJ, Goadsby PJ. Voltage-dependent calcium channels are involved in neurogenic dural vasodilation via a presynaptic transmitter release mechanism. Br J Pharmacol. 2003;140:558-566.

46. Sicuteri F. Natural opioids in migraine. In: Critchley M, Friedman A, Gorini S, Sicuteri F, editors. Advances in Neurology, volume 33. Headache: Physiopathological and Clinical Concepts. New York: Raven Press. 1982:65-74.

47. Mosnaim AD, Diamond S, Wolf ME, Freitag FG. Endogenous opioid-like peptides in headache. An overview. Headache. 1989;29:387-392.

48. Burstein R. Deconstructing migraine headache into peripheral and central sensitization. Pain. 2001;89:107-110.

49. Kelly D. Central representations of pain and analgesia. In: Kandel E, Schwartz J, editors. Principles of Neural Science. 2nd ed. New York: Elsevier Science; 1985.

50. Mosnaim AD, Chevesich J, Wolf ME, Freitag DO, Diamond S. Plasma methionine-enkephalin. Increased levels during a migraine episode. Headache. 1986;26:278-281. 
51. Diamond S, Mosnaim AD, Freitag F, Wolf ME, Lee G, Solomon G. Plasma methionine-enkephalin in patients with cluster headache. In: Rose FC, editor. Advances in Headache Research. London: John Libbey \& Co. Ltd; 1987:209-219.

52. Mosnaim AD, Puente J, Wolf ME, Callaghan OH, Busch R, Diamond S. Studies of the in vitro human plasma degradation of methionine-enkephalin. General Pharmacol. 1988;19:729-733.

53. Mosnaim AD, Nguyen TD, Tse R, Puente J, Couceyro P, Wolf ME. In vitro methionine-enkephalin degradation kinetics by human brain preparations. Neurochem Res. 2008;33:81-86.

54. Mosnaim AD, Chuang F, Wolf ME. Degradation kinetics of methionineenkephalin by human cerebrospinal fluid. In vitro studies. Am JTherap. Epub 2010 Sep 10.

55. Mosnaim AD, Puente J, Saavedra R, Diamond S, Wolf M. In vitro human plasma leucine-enkephalin degradation is inhibited by a select number of drugs with the phenothiazine molecule in their chemical structure. Pharmacology. 2003;67:6-13.

56. Mosnaim AD, Puente J, Hoang C, Ranade V, Wolf ME. Inhibition of human plasma leucine-enkephalin aminopeptidase hydrolysis by various endogenous peptides and a select number of clinically used drugs. Am J Therap. 2004;11:459-465

57. Ranade VR, Wolf ME, Puente J, Valenzuela MA, Mosnaim AD. Phenothiazine molecule provides the basic chemical structure for various classes of pharmacotherapeutic agents. Am J Therap. 2006;13: 261-273.
58. Mosnaim AD, Saavedra R, Wolf ME. Bacitracin-sensitive aminopeptidase(s) degradation of methionine-enkephalin by human brain putamem and hippocampus preparations. Inhibition by phenothiazine drugs. Am J Therap. 2009;16:512-516.

59. Blandini F, Rinaldi L, Tassorelli C, et al. Peripheral levels of BDNF and NGF in primary headaches. Cephalalgia. 2006;26:136-142.

60. Sarchielli P, Mancini ML, Floridi A, et al. Increased levels of neurotrophins are not specific for chronic migraine: evidence from primary fibromyalgia syndrome. J Pain. 2007;8:737-745.

61. Capelle H-H. Neurotrophins in the cerebrospinal fluid of patient cohorts with neuropathic pain, nociceptive pain, or normal pressure hydrocephalus. Clin J Pain. 2009;25:729-733.

62. Munno I, Centonze V, Marinaro M, et al. Cytokines and migraine: increase of IL-5 and IL-4 plasma levels. Headache. 1998;38:465-467.

63. Fidan I, Yuksel S, Ymir T, Irkec C, Nur Aksakai F. The importance of cytokines, chemokines and nitric oxide in pathophysiology of migraine. J Neuroimmunology. 2006;171:184-188.

64. Bruno PP, Carpino F, Carpino G, Zicari A. An overview on immune system and migraine. Eur Rev Med Pharmacol Sci. 2007;11: 245-248.
Pragmatic and Observational Research

\section{Publish your work in this journal}

Pragmatic and Observational Research is an international, peer-reviewed, open access journal that publishes data from studies designed to reflect more closely medical interventions in real-world clinical practice compared with classical randomized controlled trials (RCTs). The manuscript

\section{Dovepress}

management system is completely online and includes a very quick and fair peer-review system. 